\title{
The influence of oil film thickness on the gear impact dynamics of friction disc
}

\author{
Zheng $\mathrm{Hu}^{1,{ }^{*}}$, Shuai Wang ${ }^{2}$, Meiqiu Song ${ }^{1}$, Yi Xu ${ }^{1}$, Keyan Ning ${ }^{1}$ \\ ${ }^{1}$ Science and Technology on Vehicle Transmission Laboratory, China North Vehicle Research \\ Institute, Beijing, China, 100072 \\ ${ }^{2}$ China aviation planning and design institute(group)co,.LTD, Beijng, China, 100120 \\ *huzhengvip@126.com
}

Key word: friction disc, dynamic model, impact load, oil film thickness

\begin{abstract}
According to the working mechanism of wet clutch and brake, nonlinear dynamics of teeth of friction disc strongly influences the dynamic behaviours. By utilizing Hertz contact theory and elastohydrodynamic lubrication theory the thickness and equivalent stiffness of oil film between inner gear of friction disc and outer spline in center shaft are being analyzed and the corresponding dynamic model and kinematic differential equations are established. Calculations and analysis are carried out on the dynamic model and finally the difference of dynamic response is being compared on geared dynamic systems with or without the oil film. The result showed that oil film affects the impact loads of gears in a large scale. It has been verified that the method is very applicable to the design of wet clutch and brake.
\end{abstract}

\section{Introduction}

Clutch and brake with wet multi disc friction pairs system is widely used in various kinds of vehicles. The clutch and brake essentially consists of friction discs, radially fixed by means of a spline on a central shaft, and separator discs radially fixed in a housing. The teeth are engaged by splines on a shaft and on the housing, respectively. However, most of the clutches and brakes used in automotive and heavy-duty equipment operate in transient mode, at rapidly varying sliding speed, which would produce large impact loads between gears. Large impact loads can lead the gear teeth fatigue fracture and gear surface plastic deformation. Therefore, how to reduce impact loads is an important work to extend the lifetime of wet multi disc friction pairs system in wet clutch and brake. Some study results show under the lubricated conditions wet clutch and brake for automatic transmission applications strongly influences the dynamic behaviour of the entire machine or vehicle including the transmission[1,2]. In this work, we mainly studied the impact dynamics between inner gear of friction disc and outer spline in center shaft with or without the consideration of squeezed oil film. First, based on the Hertz contact theory, a model for predicting the impact load history between inner gear of friction disc and outer spline in center shaft were derived. Then the dynamical behavior of a modified model of coupling the effect of oil film thickness is studied systematically.

\section{Impact dynamic model}

Hertz contact theory provides a very good approximation for collisions between hard compact bodies where the contact region remains small in comparison with the size of either body[3]. Thus impact loads between inner gear of friction disc and outer spline in center shaft based on Hertz contact theory is as follows:

$$
F= \begin{cases}-\left(1+p\left(\dot{x}_{1}-\dot{x}_{2}\right)\right) H\left(x_{1}-x_{2}-d / 2\right)^{3 / 2} & x_{1}-x_{2}-d / 2>0 \\ \left(1+p\left(\dot{x}_{2}-\dot{x}_{1}\right)\right) H\left(x_{2}-x_{1}-d / 2\right)^{3 / 2} & x_{2}-x_{1}-d / 2>0 \\ 0 & \text { otherwise }\end{cases}
$$


where $p$ is impact energy loss coefficient, $x_{1}$ and $x_{2}$ is friction disc and center shaft displacement, respectively, $d$ is backlash, $H$ is defined as follow:

$$
H=(4 / 3) E r^{1 / 2} \text {. }
$$

where $E$ is equivalent elastic modulus of meshing gear, $r$ is the equivalent curvature radius.

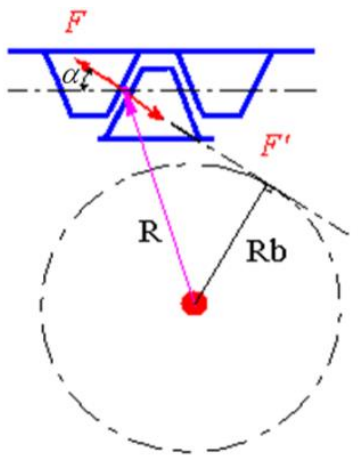

Fig.1 Impact processes between friction disc and center shaft

\begin{tabular}{ll} 
Table 2 Input data & \\
\hline Item & Value \\
\hline Teeth number $\mathrm{n}$ & 154 \\
pitch radius $R(\mathrm{~mm})$ & 231 \\
Pressure angle $\alpha$ & $20^{\circ}$ \\
speed fluctuation frequency $f(\mathrm{~Hz})$ & 104 \\
fluctuation amplitude of angular speed & 4.378 \\
$A(\mathrm{rad} / \mathrm{s})$ & \\
oil film viscosity $\eta\left(\mathrm{Ns} / \mathrm{m}^{2}\right)$ & 289.1 \\
Young modulus $E(\mathrm{GPa})$ & 210 \\
Backlash $(\mathrm{mm})$ & 0.75 \\
\hline
\end{tabular}

Impact processes between inner gear of friction disc and outer spline in center shaft is shown in Fig.1. During the center shaft rotating gradually till a steady rpm, friction disc would concentrically rotate with center shaft for inertial forces. Thus, the impact dynamic model is established under friction disc concentric to center shaft assumption. The tooth style of friction disc and outer spline in center shaft mostly is involute gear. In an involute spline gear, the profiles of the teeth are involutes of a circle. The line of the impact load follows the generating line, and is thus tangent to the base circle. $F$ and $F^{\prime}$ is gear impact load and opposite reaction, respectively.

The center shaft would produce torsional vibration and make fluctuation of speed. So the angular speed can be calculated by the following equation:

$$
\dot{\theta}=\dot{\theta}_{0}+A \sin (2 \pi f t) \text {. }
$$

where $\dot{\theta}$ is angular speed of the center shaft, $\dot{\theta}_{0}$ is steady angular speed, $A$ is fluctuation amplitude of angular speed, $f$ is speed fluctuation frequency.

The center drive shaft transmits torque to friction discs primarily through the spline. Presented below are the generic dynamic equations for friction disc and center shaft:

$$
\begin{aligned}
& \ddot{\theta}_{1}=2 \pi f A \cos (2 \pi f t)+\left(n F R_{b}-C_{1} \dot{\theta}_{1}\right) / J_{1} . \\
& \ddot{\theta}_{2}=\left(-n F R_{b}-C_{2} \dot{\theta}_{2}\right) / J_{2} .
\end{aligned}
$$

As shown in Fig.1, the equation (1) can be modified as follow:

$$
F=\left\{\begin{array}{ll}
-\left[1+p\left(\dot{\theta}_{1}-\dot{\theta}_{2}\right) R \cos (\alpha)\right] H\left[\left(\theta_{1}-\theta_{2}-d^{\prime} / 2 R\right) R \cos (\alpha)\right]^{3 / 2} & \theta_{1}-\theta_{2}-d^{\prime} / 2 R>0 \\
{\left[1+p\left(\dot{\theta}_{2}-\dot{\theta}_{1}\right) R \cos (\alpha)\right] H\left[\left(\theta_{2}-\theta_{1}-d^{\prime} / 2 R\right) R \cos (\alpha)\right]^{3 / 2}} & \theta_{2}-\theta_{1}-d^{\prime} / 2 R>0 \\
0 & \text { otherwise }
\end{array} .\right.
$$

where $J_{1}$ and $J_{2}$ is center shaft and friction disc rotational inertia, respectively, $\theta_{1}$ and $\theta_{2}$ is angular displacement of center shaft and friction disc, $C_{1}$ and $C_{2}$ is the damping coefficient of the central shaft and friction discs, $R$ is pitch radius, $d^{\prime}$ is the equivalent backlash, $\mathrm{n}$ is teeth number, $\alpha$ is pressure angle.

Modified impact dynamic model with the consideration of oil film

The intermediate layer of oil between two approaching surfaces gives rise to a damping effect 
known as squeeze film damping. In this paper, the oil squeeze effect in the gap has been modeled under the following tribological assumptions:(1) The cylinders approach each other without any slip velocity,(2) The oil film viscosity is assumed to be constant.

During the impacts between the teeth of the spline gear pairs, the oil squeeze force[4] is expressed by

$$
W=-\beta \frac{\eta B^{3} L}{h^{3}} \cdot \frac{d h}{d t}
$$

where $h$ is the oil film thickness between spline gear pairs, $L$ and $B$ is the contact radial and axial length, respectively, $\eta$ is oil film viscosity, the item $\frac{d h}{d t}$ is the effect of oil film squeezing, which can be regarded as the speed difference $\Delta v$ between center shaft and friction discs, $\beta$ is oil leakage coefficient, which depend upon the ratio of $B / L$.

The slope of the oil squeeze force-oil film thickness curve is the oil film stiffness.

$$
K_{w}=3 \beta \frac{\eta B^{3} L}{h^{4}} \cdot \Delta v
$$

Computation of the stiffness of a spline coupling involves both deformation stiffness and oil film stiffness. The total equivalent stiffness can be obtained by

$$
K=1 /\left(1 / K_{w}+1 / H\right) \text {. }
$$

The modified equation (2) is given as

$$
F=\left\{\begin{array}{ll}
-\left[1+p\left(\dot{\theta}_{1}-\dot{\theta}_{2}\right) R \cos (\alpha)\right] K\left[\left(\theta_{1}-\theta_{2}-d^{\prime} / 2 R+h_{o}\right) R \cos (\alpha)\right]^{3 / 2} & \theta_{1}-\theta_{2}-d^{\prime} / 2 R+h_{o}>0 \\
{\left[1+p\left(\dot{\theta}_{2}-\dot{\theta}_{1}\right) R \cos (\alpha)\right] K\left[\left(\theta_{2}-\theta_{1}-d^{\prime} / 2 R+h_{o}\right) R \cos (\alpha)\right]^{3 / 2}} & \theta_{2}-\theta_{1}-d^{\prime} / 2 R+h_{o}>0 \\
0 & \text { otherwise }
\end{array} .\right.
$$

\section{Numerical simulation}

According to hydrodynamic lubrication, variation of oil film thickness during theoretic calculation is $1-100 \mu \mathrm{m}$. The oil film always has the same width which is equal to the minimum face width of the gear pair. In this paper, it has been supposed that the ratio of extension $B / L$ is equal to 1 . So the $\beta$ value is 0.421 , which are obtained by Cameron[5]. Based on the modified analytical model in this paper, effects of the oil film thickness on the impact load of gear pair are able to be calculated and investigated. Speed fluctuation frequency and fluctuation amplitude of angular speed are obtained by friction discs experimental equipment. The main parameters used in this paper are shown in Table 2.

The case where oil film thickness $h$ increasing gradually from 0 to $75 \mu \mathrm{m}$ with interval of 25 $\mu \mathrm{m}$ are simulated to investigate the effect of oil film thickness on gear impact loads. The corresponding results for theoretic calculation are shown in Fig. 2. It can be seen that the maximum positive impact load is $945.39 \mathrm{~N}$, the maximum negative impact load is $-976.42 \mathrm{~N}$ when the oil film thickness is zero as shown in Fig 2a. This would produce positive/negative impact load when the speed of friction disc and center shaft have the same/opposite direction. During the oil film thickness is about $25 \mu \mathrm{m}$, the maximum positive impact load decreases to $867.6 \mathrm{~N}$ and the maximum negative impact load decreases to $-867.8 \mathrm{~N}$ as shown in Fig. $2 \mathrm{~b}$. The impact loads are displayed in Fig.2c when the oil film thickness is $50 \mu \mathrm{m}$. The impact loads is $503.1 \mathrm{~N}$ and $-503.5 \mathrm{~N}$, respectively. The extent of decrease is about $50 \%$. When the oil film thickness increases to $75 \mu \mathrm{m}$, the value of impact loads keep decrease from Fig. $2 \mathrm{~d}$. 

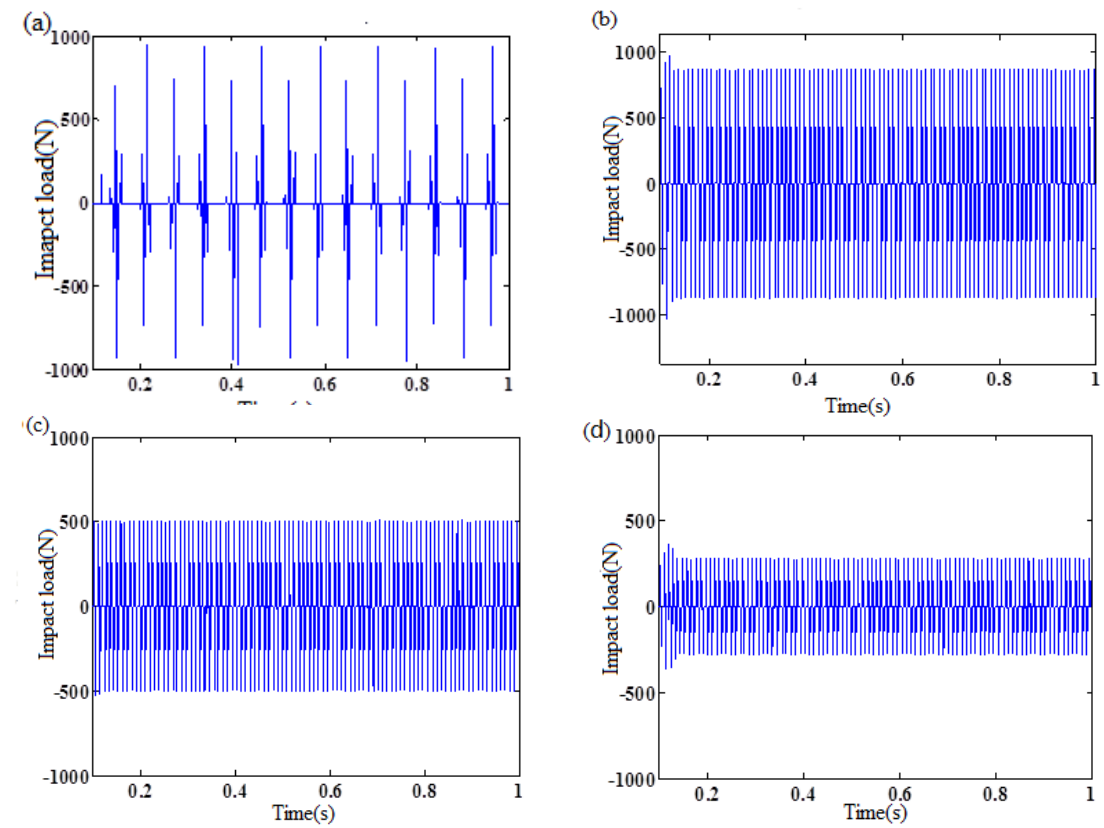

Fig.2 Impact load under variation of oil film thickness.(a) $0 \mu \mathrm{m}$,(b) $25 \mu \mathrm{m}$, (c) $50 \mu \mathrm{m}$, (d) $75 \mu \mathrm{m}$
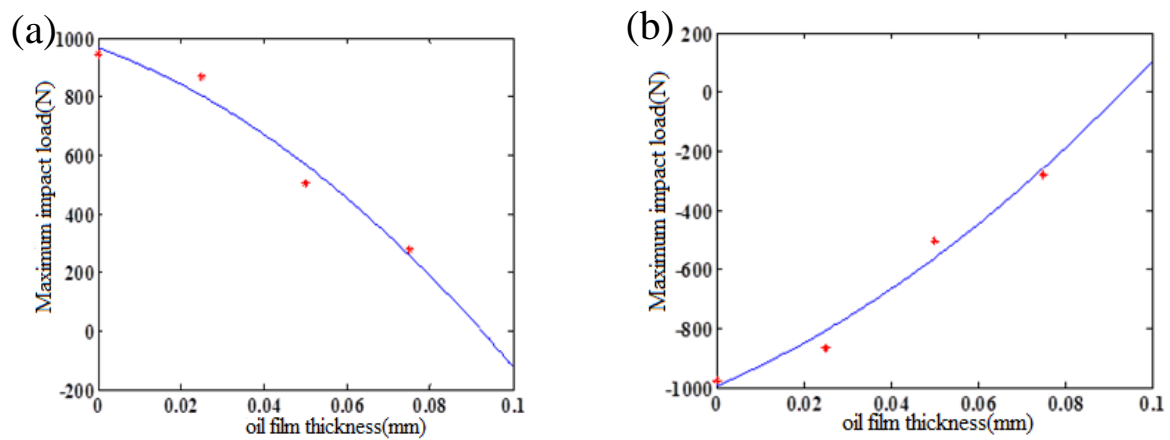

Fig.3 Maximum impact load with different oil film thickness.(a) positive impact load, (b) maximum negative impact load

The second degree polynomial fitting curves showing the trends of impact load along oil film thickness are displayed in Fig.3. It can be seen clearly that impact loads decrease with increasing of oil film thickness. As the oil film becomes thicker, the effect of oil film squeezing becomes more and more obvious.

\section{Summary}

A impact dynamic model of friction disc is established based on Hertz contact theory. According to elastohydrodynamic lubrication theory and impact dynamic model, the effects of oil film between inner gear of friction disc and outer spline in center shaft are being analyzed and the corresponding dynamic model are obtained. Oil film gives rise to a damping effect on the impact process of friction discs. Impact loads decrease with the increasing of oil film thickness.

\section{References}

[1] R Brancati, E Rocca and R Russo, Proc. IMechE, 219 (2005) 1075-1083.

[2] Pinkus, O. and Sternlicht, B. Theory of Hydrodynamic Lubrication, 1961 (McGraw-Hill, London).

[3] K.L. Johnson, Contact mechanics. Cambridge University Press, Ninth printing 2003.

[4] Wen SZ. Principles of tribology. Beijing: Tsinghua University Press, 1990.

[5] A.Cameron, A S L E Transactions, 1:2 (1958) 248-253. 